\title{
Sources of dissolved organic carbon (DOC) in a mixed land use catchment (Exe, UK)
}

Article

Accepted Version

Creative Commons: Attribution-Noncommercial-No Derivative Works 4.0

Ritson, J. P., Croft, J. K., Clark, J. M., Brazier, R. E., Templeton, M. R., Smith, D. and Graham, N. J. D. (2019) Sources of dissolved organic carbon (DOC) in a mixed land use catchment (Exe, UK). Science of the Total Environment, 666. pp. 165-175. ISSN 0048-9697 doi:

https://doi.org/10.1016/j.scitotenv.2019.02.228 Available at https://centaur.reading.ac.uk/82341/

It is advisable to refer to the publisher's version if you intend to cite from the work. See Guidance on citing.

To link to this article DOI: http://dx.doi.org/10.1016/j.scitotenv.2019.02.228

Publisher: Elsevier

All outputs in CentAUR are protected by Intellectual Property Rights law, including copyright law. Copyright and IPR is retained by the creators or other copyright holders. Terms and conditions for use of this material are defined in the End User Agreement. 


\section{CentAUR}

Central Archive at the University of Reading

Reading's research outputs online 


\section{Accepted Manuscript}

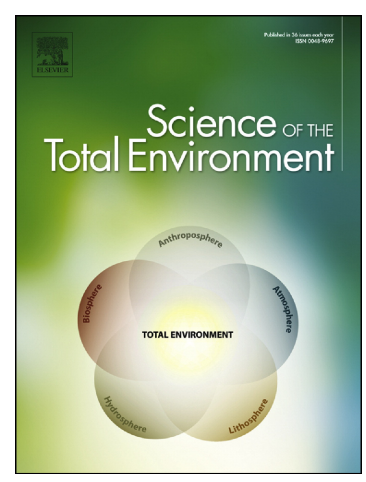

J.P. Ritson, J.K. Croft, J.M. Clark, R.E. Brazier, M.R. Templeton, D. Smith, N.J.D. Graham

Sources of dissolved organic carbon (DOC) in a mixed land use catchment (Exe, UK)

PII:

S0048-9697(19)30722-3

DOI: https://doi.org/10.1016/j.scitotenv.2019.02.228

Reference: STOTEN 30974

To appear in: Science of the Total Environment

Received date: 31 October 2018

Revised date: 12 February 2019

Accepted date:

15 February 2019

Please cite this article as: J.P. Ritson, J.K. Croft, J.M. Clark, et al., Sources of dissolved organic carbon (DOC) in a mixed land use catchment (Exe, UK), Science of the Total Environment, https://doi.org/10.1016/j.scitotenv.2019.02.228

This is a PDF file of an unedited manuscript that has been accepted for publication. As a service to our customers we are providing this early version of the manuscript. The manuscript will undergo copyediting, typesetting, and review of the resulting proof before it is published in its final form. Please note that during the production process errors may be discovered which could affect the content, and all legal disclaimers that apply to the journal pertain. 


\section{Sources of dissolved organic carbon (DOC) in a mixed land use catchment (Exe, UK)}

Authors: J.P. Ritson ${ }^{a^{*}}$, J.K. Croft ${ }^{\mathrm{a}}$, J.M. Clark ${ }^{\mathrm{b}}$, R.E. Brazier ${ }^{\text {, }}$ M.R. Templeton ${ }^{\mathrm{a}}$, D. Smith ${ }^{\text {d, N.J.D. }}$ Graham $^{\mathrm{a}}$

a Department of Civil and Environmental Engineering, Imperial College London, South Kensington, London SW7 2AZ,UK

${ }^{\mathrm{b}}$ Department of Geography and Environmental Science, School of Archaeology, Geography and Environmental Science, The University of Reading, Whiteknights, PO Box 227, Reading RG6 6AB, UK

${ }^{c}$ Geography, College of Life and Environmental Sciences, University of Exeter, EX4 4RJ, UK

${ }^{\mathrm{d}}$ South West Water Ltd., Peninsula House, Rydon Lane Exeter, Devon EX2 7HR, UK.

* Corresponding author: j.ritson12@imperial.ac.uk, Department of Civil and Environmental Engineering, Imperial College London, South Kensington, London SW7 2AZ, UK 


\section{Abstract}

Many catchment management schemes in the UK have focussed on peatland restoration to improve ecosystem services such as carbon sequestration, water quality and biodiversity. The effect of these schemes on dissolved organic carbon (DOC) flux is critical in understanding peatland carbon budgets as well as the implications for drinking water treatment. In many catchments, however, peatland areas are not the only source of DOC, meaning that their significance at the full catchment scale is unclear. In this paper we have evaluated the importance of different land uses as sources of DOC by combining three datasets obtained from the Exe catchment, UK. The first dataset comprises a weekly monitoring record at three sites for six years, the second, a monthly monitoring record of 25 sites in the same catchment for one year, and the third, an assessment of DOC export from litter and soil carbon stocks. Our results suggest that DOC concentration significantly increased from the peaty headwaters to the mixed land-use areas (ANOVA F=12.52, $\mathrm{p}<0.001, \mathrm{df}=2$ ), leading to higher flux estimates at the downstream sites. We present evidence for three possible explanations: firstly, that poor sampling of high flows may lead to underestimation of DOC flux, second, that there are significant sources of DOC besides the peatland headwaters, and finally, that biological- and photodegradation decreases the influence of upstream DOC sources. Our results provide evidence both for the targeting of catchment management in peatland areas as well as the need to consider DOC from agricultural and forested areas of the catchment.

Key words: Dissolved organic carbon (DOC), catchment management, flux estimates 


\subsection{Introduction}

Peatland catchments have been the focus of much research in recent years due to their global importance as carbon stores (Billett et al., 2010). Dissolved organic carbon (DOC) represents an important carbon flux with the highest concentrations and fluxes observed in peatland catchments (Aitkenhead and McDowell, 2000), meaning that the transport and transformation of DOC in inland waters needs to be considered in global carbon models (Cole et al., 2007). DOC concentrations have been rising in many surface waters across northern Europe and North America as catchments recover from acidification (Monteith et al., 2007). Future DOC levels may be altered further by low peatland water tables favouring decomposition of organic matter and DOC production, particularly in catchments which have been drained or degraded (Freeman et al., 2001).

As well as being important for carbon budgets, DOC is also an important parameter for drinking water treatment as it can cause problems with taste, odour and discolouration. Further to this, DOC which is not removed during treatment can react to form disinfection by-products (DBPs) which are regulated in the UK as they are potential carcinogens (Nieuwenhuijsen et al., 2009). As well as posing a risk of regulatory failure, DOC impacts operational costs of treatment works by increasing coagulant demand and sludge production whilst decreasing filter run times (Edzwald, 1993;

Eikebrokk et al., 2004). How DOC quantity and quality, in terms of ease of removal during treatment, will change in the future is unclear, however greater seasonality due to altered temperature and rainfall patterns, increased influence from algal blooms and continued recovery from acidification are all plausible scenarios (Ritson et al., 2014). In response, many water companies in the UK, Europe and North America have invested in catchment management schemes focussed on restoring drained and degraded peatland areas as a way of improving raw water quality, biodiversity and carbon sequestration (Bonn et al., 2014; Parry et al., 2014; Yu et al., 2017), potentially limiting the need for future capital investment in new treatment technologies. 
Although some catchments in the UK drain exclusively peatland areas, there are many which cover a number of land uses with potential influences from agriculture, forestry and urban areas. Studies concerning catchment scale influences on DOC concentration and chemical character often highlight percentage wetland cover in the catchment as a key parameter for predicting the concentration of DOC, however significant associations with DOC concentrations have also been observed for cropland, woodland and urban extent (Noacco et al., 2017; Wilson and Xenopoulos, 2008; Yang et al., 2017). Furthermore, DOC which enters rivers in the headwaters is subject to a number of mechanisms of removal and transformation including photolysis, bacterial utilisation and flocculation/sedimentation (Jones et al., 2016). These mechanisms can act together to limit the variability in DOC concentration as stream order increases, leading to the concept of rivers acting as chemostats (Creed et al., 2015) wherein variation in DOC concentration and quality is muted by the combined effect of the processes listed above. This effect can be accentuated where waters of differing DOC and nutrient concentration meet, creating hotspots of higher rates of decomposition (Palmer et al., 2016). The influence of peatland areas in the headwaters is therefore unclear at the full catchment scale as decreases in DOC concentrations have been reported in the UK when measured at the catchment outlet (Worrall et al., 2018).

Where sub-catchments of differing land use join the main channel close to points of drinking water abstraction, these may represent highly significant sources of DOC as removal processes are likely much less than that observed elsewhere in lakes and reservoirs (Köhler et al., 2013). We therefore hypothesised that sub-catchments of urban, woodland and agricultural land use close to the point of abstraction may act to increase DOC flux, resulting in a decreasing peatland influence on catchment carbon budgets as the complexity of land use within the catchment increases.

To test this hypotheses, we evaluated weekly grab sampling data collected by a water company from 2012-2017 at three sites on the river Exe, UK, a mixed land use catchment from which direct abstraction occurs for drinking water production at two of the sampling points (Bolham and 
Brampford Speke). This represents an unusually high sampling frequency dataset as characterisation of DOC in rivers is commonly based on a monthly sampling frequency (e.g. United Kingdom Acid Waters Monitoring Network). The monitoring programme aimed to ascertain whether DOC concentration, flux and trends were influenced by peatland restoration works occurring in the peatland headwaters of the catchment (detailed in Grand-Clement et al., 2013). To supplement the long-term monitoring data, we also performed a monthly grab sampling survey in 2016-2017 for 25 sites across the catchment to identify the contribution of DOC made by each sub-catchments to evaluate peatland and non-peatland sources of DOC. This part of the study was undertaken at lower temporal resolution but offered an unusually high spatial resolution compared to previously published datasets. Finally, we compared the amount and biodegradation of extractable DOC from litter and soils in both a peatland and a woodland area within the catchment to ascertain differences in the environmental persistence of DOC from contrasting land uses and to establish further understanding of the connectivity of DOC sources with concentrations and loads in surface waters. Peatland and woodland sites were selected as they were identified in the monthly monitoring program as contributing high DOC concentrations. Whilst extractable DOC data is more widely available for soils and vegetation, there is a growing awareness of the need to consider the persistence of this DOC. Our dataset adds important information in this area.

\subsection{Material and methods}

The Exe catchment drains an area of $600.9 \mathrm{~km}^{2}$ at the lowest gauging station used in this study (Thorverton 45001) with a mean daily flow in the period 1956-2016 of $16.2 \mathrm{~m}^{3} \mathrm{~s}^{-1}$ (NRFA data). The catchment geology contains mainly Devonian sandstones and Carboniferous Culm Measures with land use typically moorland and forestry in the northern headwaters and increasing agricultural and urban influence further down the catchment. Climatically, the catchment shows a significant northsouth gradient in both temperature and rainfall with Liscombe climate station in the northern headwaters recording a mean annual temperature of $5.8-12.1^{\circ} \mathrm{C}$ and mean annual rainfall of 
$1,445.2 \mathrm{~mm}$, whereas the Exeter Airport climate station near the mouth of the Exe has a mean annual temperature of $6.8-14.8^{\circ} \mathrm{C}$ and mean annual rainfall of $784.9 \mathrm{~mm}$ (UK Met Office figures). Please see supplmetary figure for locations of the climate stations and gauging stations used. The area is part of a catchment management scheme which is being studied as part of the 'Upstream Thinking' program funded by South West Water, detailed in Grand-Clement et al., (2013).

\subsection{Monitoring programme and flux estimates}

Weekly grab sampling was undertaken by South West Water during the period October 2011 to December 2017 for three sites: Exebridge (51.009694, -3.526232), Bolham (50.9277, -3.49738) and Brampford Speke $(50.76412,-3.51811)$. To estimate DOC flux we obtained data from the National River Flow Archives (NRFA) which operate gauging stations near the sites. At Brampford Speke we used 'Exe at Thorverton (45001)' which is approximately $6.05 \mathrm{~km}$ upstream and had a mean gauged daily flow for the period of interest of $17.61 \mathrm{~m}^{3} \mathrm{~s}^{-1}$. For Bolham we used the 'Exe at Thorverton (45002)' gauging station which is approximately $2.75 \mathrm{~km}$ upstream from the sampling site and had a mean gauged daily flow for the period of interest of $12.42 \mathrm{~m}^{3} \mathrm{~s}^{-1}$. At the Exebridge site there is no gauging station after the confluence of the Exe and the Barle, however nearby gauging stations before the confluence offer a method of estimating the flow. We therefore summed the flow from the gauging stations 'Barle at Brushford (45011)' and 'Exe at Pixton (45009)' to give an estimate of flow after the confluence. This gave a mean gauged daily flow for the period of interest of $10.36 \mathrm{~m}^{3} \mathrm{~s}$

Load was estimated from the weekly grab sampling data via Method 5 (Walling and Webb, 1985) shown in Eq 1.

$$
L o a d=K Q_{r}\left(\frac{\sum_{i=1}^{n} C_{i} Q_{i}}{\sum_{i=1}^{n} Q_{i}}\right)
$$

Where $\mathrm{K}$ is the time conversion factor, $\mathrm{Q}_{r}$ is the annual mean discharge from the continuous daily flow record, $C_{i}$ is the instantaneous concentration and $Q_{i}$ is the instantaneous discharge. We then 
estimated the standard error using published methods (Hope et al., 1997) which are summarised in Eq 2 and Eq 3.

$$
\text { Standard Error }(\text { Load })=F \cdot \sqrt{\operatorname{VarC}}
$$

Eq 2.

Where $F$ is the total annual flow from the continuous daily record and $\operatorname{Var} C_{F}$ is the variance in the flow-weighted mean DOC concentration.

$$
\operatorname{Var}_{F}=\left[\Sigma\left(C_{i}-C_{F}\right)^{2} Q_{i} /_{Q_{n}}\right] \Sigma^{Q_{i}^{2}} / Q_{n}^{2}
$$

Eq 3.

Where $Q_{n}$ is defined as the sum of instantaneous flow measurements. Note, the standard error calculated by this method focusses mainly on errors in the flow weighted mean DOC concentration and does not include, for example, errors in flow gauging or discrepancies caused by the distance from the sampling point to the flow gauge.

\subsection{Catchment survey}

Between November 2016 and October 201725 sites in the Exe catchment were grab-sampled 12 times with two replicates on each date. Samples were returned to the laboratory on ice, filtered with pre-ashed GF/F filters within 24 hours and analysed for DOC concentration and UV-Vis absorbance. Sites were selected to include the major tributaries of the Exe as well as to cover most major landuse classes. We also included the inlet and outlet of a small-scale fish farm, of which there are many in the catchment, to study the effect of aquaculture on downstream DOC quantity and quality ('Fishery' site in Fig 1.). The fishery rears rainbow trout (Oncorhynchus mykiss) for the stocking of fishing ponds and has an annual production of $150 \mathrm{t}$. We refer to this as small-scale in comparison to the more heavily researched marine aquaculture systems which can be up to $2,500 \mathrm{t}$ production in the UK and 4,500 $\mathrm{t}$ in Norway (Salama and Murray, 2011). The locations of the 25 sites as well as 
sites for the weekly monitoring programme are shown in Figure 1 alongside the peatland areas in the catchment, determined using the Natural England Priority Habitat Inventory dataset (note: Exebridge was used in the weekly monitoring programme but not the catchment survey). Abstraction for drinking water production occurs at Bolham and Brampford Speke.

[Figure 1]

Figure 1: Map showing the locations of the 25 sites in the catchment survey of the Exewith the peatland areas highlighted in red. *Denotes site was used in the weekly monitoring programme.

Details of the catchment area and land use of each sampling site are available in the Supplementary Information (Table 1). The distribution of different land use classes is also shown in a map of the catchment in the supplementary information. To assess the contribution of different land used to DOC concentration and properties, we performed automated linear modelling in SPSS V24 (IBM) using the land use percentages in for the sub-catchments identified in Supplementary Table 1. We performed this analysis on the 15 sub-catchments as samples taken from within the main channel were not independent of each other. All predictors were entered based on the best subsets procedure with adjusted $r^{2}$ used as the criteria for entry and removal. We then compared the best possible models using the variance explained (adjusted $r^{2}$ ).

\subsection{Assessment of carbon stocks under different land uses}

To assess the contributions of soil and litter sources of riverine DOC under different land uses we measured carbon stocks, extractable DOC and the persistence of this DOC with respect to microbial mineralisation. We assessed two sites; Spooners, a peatland site, and Tarr Steps, an oak woodland with freely draining acid loam soils. These were selected as these types of sub-catchment were identified in the monthly sampling program as contributing high DOC concentrations. 
On 8/11/18 we performed field sampling at the Spooners peatland site $(51.12238,-3.75307)$ at approximately $424 \mathrm{~m}$ of elevation above sea level. Five sampling points were selected using a stratified random method in a 1 ha area and the following measurements were taken: peat depth (three replicates at $1 \mathrm{~m}$ from sampling point), peat cores (two replicates) and destructive collection of above-ground biomass (two replicates of $25 \mathrm{~cm}^{2}$ ). This gave a total of 15 peat depth measurements, 10 peat cores and 10 litter collections. Samples were shipped on ice to the laboratory where the peat cores were split into $0-10 \mathrm{~cm}$ and $10-20 \mathrm{~cm}$ depths before measurement of bulk density, loss on ignition (LOI), C:N and Water Extractable Organic Matter (WEOM). The subsequent WEOM sample was analysed for $\mathrm{pH}, \mathrm{DOC}$ concentration, UV-Vis absorption and biodegradable dissolved organic carbon (BDOC) concentration. The litter samples were oven dried at $60{ }^{\circ} \mathrm{C}$ until constant weight and then sorted by hand into individual species and weighed. For Sphagnum we did not attempt identification of each species but instead recorded a class of mixed Sphagnum Spp.

On $9 / 11 / 18$ we performed field sampling at the Tarr Steps forested site $(51.07713,-3.61778)$, a site of specific scientific interest (SSSI) of ancient semi-natural woodland at approximately $235 \mathrm{~m}$ of elevation. Five sampling points were selected using a stratified random method and the following measurements were taken: bulk density at $0-10 \mathrm{~cm}$ and $10-20 \mathrm{~cm}$ (two replicates), soil samples at each depth (two replicates) and destructive collection of above-ground biomass (two replicates of 25 $\mathrm{cm}^{2}$ ). This gave a total of 20 bulk density measurements, 20 soil samples and 10 litter collections. Our sampling methodology was based on the European Commission methodology for assessing soil carbon stocks (Stolbovoy et al., 2007) and we followed these protocols in sampling. Samples were shipped on ice to the laboratory where they were analysed for the same parameters as the peatlands samples. At each site we also performed a survey of dominant vegetation types present (Supplementary Information). The litter samples were oven dried at $60^{\circ} \mathrm{C}$ until constant weight and then sorted by hand into individual species and weighed. For the litter samples we also analysed C:N and WEOM (five replicate extractions of a bulked litter sample) as well as the $\mathrm{pH}$, UV-Vis absorbance 
and BDOC of this WEOM. We did not complete this additional analysis for the peatland site as we have already published data concerning C:N, WEOM and BDOC for these species (Ritson et al., 2016).

At the same time as the vegetation and soil sampling we took grab samples from the river immediately downstream of the sampling site. At Spooners and Tarr Steps this was the same point as used in the catchment survey, however, we also included an additional sampling point at Tarr Steps which was a small tributary dominated by forest land cover $(51.081544,-3.626349$, elevation $240 \mathrm{~m})$. At each sampling point four samples were collected and shipped on ice to the laboratory where they were filtered with GF/F filters and then evaluated for $\mathrm{pH}, \mathrm{DOC}$ concentration, UV-Vis absorbance and BDOC.

\subsection{Laboratory procedures}

For the data collection described in section 2.2 and 2.3 the following protocols were followed. DOC was measured as non-purgeable organic carbon (NPOC) on samples acidified with $\mathrm{HCl}$ and filtered through pre-ashed GF/F filters on a ShimadzU TOC-V instrument which was calibrated daily. UV-Vis absorbance was measured on a Perkin Elma Lambda 3 instrument using a $1 \mathrm{~cm}$ quartz cuvette between 200 and $600 \mathrm{~nm}$. The specific absorbance, SUVA, was calculated as the absorbance at 254 $\mathrm{nm}$ in units of $\mathrm{m}^{-1}$ divided by the NPOC content $\left(\mathrm{mgCl}^{-1}\right)$ and is used as an indicator of aromaticity of the DOC (Weishaar et al., 2003). BDOC was measured as the loss of NPOC after a one-week incubation at $20^{\circ} \mathrm{C}$ in the dark with added nutrients and a standardised inoculum (McDowell et al., 2006). WEOM was obtained by performing a 24-hour extraction on a shaker table with reverse osmosis water at a 20:1 water to sample ratio. LOI was calculated as the loss of mass on dry samples after heating to $550^{\circ} \mathrm{C}$ for four hours. Bulk density was measured by weight of soil contained in a 50 $\mathrm{mm}$ diameter, $50 \mathrm{~mm}$ height soil density ring for the forest soil and by displacement of water for the peat soil. For elemental analysis sub-samples of dry litter and soil were ground to a fine powder using a Tema mill and analysed in duplicate on a Thermoflash $\mathrm{CHN}$ analyser at the University of 
Reading. Aspartic Acid was used for calibration and certified reference material for plant and peat soil were run every 15 samples.

For the weekly grab sampling described in section 2.1, analysis was performed by South West Water. For the period to July 2015 DOC analysis was performed on samples filtered to $0.45 \mu \mathrm{m}$ on a HachLange IL550 thermal combustion instrument. From July 2015 to the end of the dataset DOC was analysed by a Shimadzu TOC-L thermal combustion instrument. As the DOC measurements were obtained from different laboratories the values presented in different sections may not be directly comparable, however we used the values obtained by South West Water to target the work in the catchment and do not compare the absolute values in our subsequent analysis.

\subsection{Results}

\subsection{Long-term monitoring dataset}

As a first step to assess how representative the grab sampled data are, we plotted the dates of sampling against the hydrograph from gauged daily flow data. This is shown in Figure 2, below.

[Figure 2]

Figure 2: Time series of gauged daily flow, Exe at Thorverton station (45001) 2012-2017 with flow at grab sampling dates highlighted by black squares. Data from NRFA.

The weekly grab sampling captures a reasonable amount of variation in flow and includes some of the high flow events, notably the peaks in December 2012. Further analysis of the distributions of the daily versus grab sample data, presented in Table 1 , shows the grab sampled data is underrepresentative of high flow conditions, evidenced by the difference in quartile ranges and skew. Despite this, the length of the dataset, sampling period and range of flow conditions covered means this weekly grab sampling offers better accuracy than others published in the literature (c.f. weekly 
sampling for one year in Yates et al., (2016) or fortnightly sampling for two years in Graeber et al., (2015)).

[Table 1]

DOC concentrations increased down the catchment with means ( \pm standard error) of $2.14 \pm 0.09$, $2.32 \pm 0.7$ and $2.70 \pm 0.08 \mathrm{mg}^{-1}$ at Exebridge, Bolham and Brampford Speke, respectively. An ANOVA test suggested a significant effect of site on DOC concentration $(F=12.52, p<0.001, d f=2)$ and Brampford Speke had a significantly higher mean than the other two sites using a Tukey test $(p=0.01)$. We analysed for differences in seasonality between the sites by performing a factorial ANOVA with factors of site and month in the model. This suggested a significant effect of month of the year on log transformed DOC concentration $(F=13.11, p<0.001, d f=11)$, however the lack of an interactive effect between site and month $(F=0.95, p=0.534, d f=22)$ suggest this affects all sites equally. The monthly means for the three sites are show in Figure 3.

[Figure 3]

Figure 3: Monthly DOC averages 2012-2017 for the three sites. Error bars at one standard error.

Using the equations described in the methods section, we were able to derive estimates of DOC flux at the three sites for the years 2012 to 2017. These are presented in Table 2, which shows the highest flux at the Brampford Speke site in all years except 2015 and 2016. Particularly high flux was observed at all sites in 2012 when significant flooding was recorded in the catchment.

[Table 2]

3.2 Catchment survey 
The flow on days where the catchment survey grab sampling was performed was typically low and is compared to the gauged daily flow data at 45001 in Table 3 and shown graphically in Figure 4 . This suggests high flow conditions were not captured and as such the catchment survey represents spatial variability in DOC quantity and quality for low flow conditions only.

[Table 3]

[Figure 4]

Figure 4: Time series of gauged daily flow at 45001 during the survey period with flow at grab sampling dates highlighted by black squares. Data from NRFA.

Analysis of log transformed DOC concentration data across the 25 sites suggest using a significant effect of site on concentration (ANOVA $F=3.81, p<0.001, d f=24$ ). As there were a large number of sites our statistical approach was to compare mean concentration from the 12 sample dates at each site to Simonsbath, the first measurement in the main channel, thus determining whether each downstream/tributary site represented a significant dilution or addition of DOC. This approach was favoured to a comparison between all sites as this would have required 325 comparisons meaning either a high chance of type 1 error or a significant loss of statistical power. We used a two-tailed Dunnet's test which suggested the Dart $(p<0.001)$, Spooners $(p=0.003)$, Hangman's Hill $(p=0.008)$, Thorverton $(p=0.008)$ and Washfield Lane $(p=0.035)$ had significantly higher DOC concentration, as shown in Figure 5.

[Figure 5)

Figure 5: Mean DOC concentration during the 2016-2017 catchment survey $(n=12) .{ }^{*}$ denotes significant difference to Simonsbath.

We next performed the same analysis for the SUVA values across the sites. This suggested a significant effect of site on SUVA (ANOVA $F=2.50, p<0.001, d f=24$ ), however none of the sites were 
significantly different to the Simonsbath site (two-tailed Dunnett test, $p>0.05$ ). The mean SUVA value across all sites was $4.57 \pm 0.12 \mathrm{~L} \mathrm{mg}^{-1} \mathrm{~m}^{-1}$, see supplementary figure for a graph of SUVA by site. As we were also interested in the potential effect of aquaculture on DOC quantity and quality we also performed an independent samples t-test on the DOC and SUVA data from the inlet and the outlet of the fishery. These tests suggested no significant difference in DOC concentration or SUVA ( $p>0.05)$. To compare urban influence directly we also compared the sites before (Bolham) and after Tiverton (Exe at Tiverton). The Exe at Tiverton site is only approximately $2.5 \mathrm{~km}$ downstream of Bolham, however in this distance the combined urban/sub-urban land use increases from $0.6 \%$ to $1.0 \%$ (see Supplementary Information). An independent samples t-test suggested no change in DOC concentration $(p=0.245)$, but a significant decrease in SUVA after the urban influence $(t=-2.335$, $p=0.03, d f=19.58)$.

We next assessed the influence of different land uses by performing automated linear modelling (ALM) for DOC concentration and SUVA values using the percentage of each land use as the predictor. It is possible for a number of different models to explain the data and therefore we compare predictors in the models which explain the most variance in the data. The best three models had adjusted $r^{2}$ values of 0.667 (based on Broadleaved woodland, Arable, Acid Grassland, Improved Grassland, Sub-urban and Neutral Grassland), 0.687 (based on Broadleaved woodland, Arable, Acid Grassland, Improved Grassland and Sub-urban) and 0.692 (Broadleaved woodland, Arable, Acid Grassland, Improved Grassland, Sub-urban and Coniferous Woodland).

The best model for DOC concentration in the $(n=15)$ sub-catchments this suggested a reasonably well fit model $\left(F=6.232, p=0.011\right.$, adjusted $\left.r^{2}=0.692\right)$ with significant predictors in the order of influence on the model of 'Broadleaved woodland (coefficient 0.394, p=0.002)', 'Arable (coefficient 0.316, $p=0.005$ )', 'Acid Grassland (coefficient 0.303, $p=0.008$ )’ 'Improved grassland (coefficient $0.287, \mathrm{p}=0.01$ )' and 'Sub-urban (coefficient $0.367,0.043$ ). The ALM process was unable to build a significant model for the influence of land use on SUVA value in the sub-catchments. 


\subsection{Comparison of DOC sources under different land uses}

Peatland and woodland sites were identified from the catchment survey as adding significantly higher DOC concentrations to the main channel and were therefore investigated further with respect to the sources of DOC in these sub-catchments.

The sampling of vegetation litter suggested the peatland site had a mean litter density of 1,212 \pm $161 \mathrm{~g} \mathrm{~m}^{-2}$ from ten replicates. The litter comprised of the following types: Molinia caerulea (74.4\%), Sphagnum Spp. (22.7\%), Juncus efussus (2.0\%), Calluna vulgaris $(0.9 \%)$ and other (0.1\%). The 'other' category was predominantly composed of feather mosses. Peat depth across all sites averaged 159.7 $\pm 3.2 \mathrm{~cm}(\mathrm{n}=15)$. The forested site has a mean litter density of $961 \pm 180 \mathrm{~g} \mathrm{~m}^{-2}$ from ten replicates. The litter comprised of Quercus petraea (36.6\%), Fagus sy/vatica (21.5\%), Pteridum aquilinum (18.9\%), woody debris (13.5\%), Corylus avellana (3.9\%) and other (5.6\%). The 'other' category was composed of unidentifiable leaf mulch, most likely in similar proportions to those detailed above. A t-test suggested the mean amounts of litter dry-weight per unit area were not significantly different between the two sites $(t=0.987, p=0.337)$. We then combined the $\% C$ values from our elemental analysis and from Ritson et al. 2016 with the data on litter amounts per $\mathrm{m}^{2}$ which give estimates of litter carbon stocks. These were $527 \pm 91 \mathrm{gC} \mathrm{m}^{-2}$ for the peatland site and $364 \pm 101 \mathrm{gC} \mathrm{m}^{-2}$ at the forested site with ten replicates at each. The litter carbon stocks were statistically similar between the two sites $(t=1.080, p=0.311)$.

The results from the experiments concerning extractable DOC and the properties of this DOC are summarised in Table 4 with the data comparing soil types summarised in Table 5.

[Table 4]

[Table 5]

By combining our data on litter and soil extractable organic carbon, its persistence (BDOC) and litter amounts we were then able to calculate totals for the litter and soil layers at each site. Data in Table 
4 was supplemented with values for peatland species in our previous work (Ritson et al., 2016) to create estimates of extractable DOC and persistent DOC, that is non-biodegradable, per $\mathrm{m}^{2}$ for each of the sites. For extractable DOC this gave a mean value of $33.07 \pm 10.78 \mathrm{~g}-\mathrm{DOC} \mathrm{m}^{2}$ for the Tarr Steps site and $17.02 \pm 4.17 \mathrm{~g}$-DOC $\mathrm{m}^{2}$ for the Spooners site with no significant difference between the sites $(t=1.39, p=0.202)$. By combining these values with the BDOC data we were then able to estimate persistent DOC from each litter source. This gave mean values of $20.50 \pm 3.73 \mathrm{~g}-\mathrm{DOC} \mathrm{m}^{2}$ at Tarr Steps and $10.65 \pm 3.31 \mathrm{~g}-\mathrm{DOC} \mathrm{m}^{2}$ at Spooners. The differences in biodegradability mean that for the riparian plots surveyed, the woodland site has significantly more persistent DOC per $\mathrm{m}^{2}(\mathrm{t}=2.42$, $\mathrm{p}=0.036)$.

We then estimated carbon stocks at the two sites using the $\% \mathrm{C}$ and bulk density at the two depths surveyed. This gave values at Tarr Steps of $28.3 \pm 15.6 \mathrm{tha}^{-1}$ in the $0-10 \mathrm{~cm}$ depth and $12.0 \pm 2.5 \mathrm{t}$ $\mathrm{ha}^{-1}$ in the $10-20 \mathrm{~cm}$ depth. At the Spooners site the soil organic carbon (SOC) stock was $40.1 \pm 2.4 \mathrm{t}$ $\mathrm{ha}^{-1}$ in the $0-10 \mathrm{~cm}$ depth and $44.8 \pm 2.2 \mathrm{t} \mathrm{ha}^{-1}$ in the $10-20 \mathrm{~cm}$ depth. Extrapolating to the full depth of the peat profile (mean $159.7 \mathrm{~cm}$ ) would suggest a total SOC stock of $714.6 \pm 32.6 \mathrm{t} \mathrm{ha}^{-1}$, however this figure should be viewed as a rough estimate as both bulk density and carbon content can vary down the peat profile (e.g. Wellock et al., 2011).

The water samples collected at the same time as the vegetation and soil samples are summarised in Table 6.

[Table 6]

There was a significant effect of site on DOC concentration (ANOVA F=31.58, $p<0.001, d f=2$ ) with Spooners being significantly higher than the other two sites (Tukey test $p<0.001$ ). The SUVA value of samples did not have a site effect (ANOVA $F=2.07, p=0.182, d f=11$ ), however the proportion of BDOC did (ANOVA F= 5.97, $p=0.022, d f=11$ ). A Tukey test suggested that Spooners had significantly higher BDOC content than Tarr Steps $(p=0.001)$ with all other comparisons being similar. 


\section{Discussion}

\subsection{Monitoring dataset}

The assessment of DOC concentration and flux estimates for the three sites suggested an increase in DOC concentration down the catchment and also highest DOC flux estimates at the Brampford Speke site in four out of the six years studied. Although the increase in DOC concentration between monitoring sites $\left(\sim 0.5 \mathrm{mg} \mathrm{l}^{-1}\right)$ is unlikely to be of great ecological significance, the impact on drinking water treatment costs is still significant. This increase in DOC concentration and flux occurs as the proportion of peatland area declines. This increase in both concentration and flux is perhaps surprising given the well documented importance of peatlands in riverine DOC budgets (Billett et al 2010) and the decreasing peatland influence down the catchment (Supplementary Table 1). Similarly, the 'river as chemostat' hypothesis suggests a decrease in DOC concentration and variance as stream order increases and processing and dilution takes place (Creed et al., 2015) which is contrary to our observations. This would suggest that either of the following may be true, that a) the monitoring dataset underestimates the peatland contribution due to the range of the hydrograph sampled, b) significant sources of DOC occur from non-peaty tributaries further down the catchment, or c) that the impact of peatland sources are minimised through microbial and photolytic processing of DOC.

We discuss evidence for hypotheses b) and c) in the sections 4.2 and 4.3 concerning the catchment survey and assessment of carbon stocks. Evidence for hypothesis a) can be found in previous studies which suggest as much as $50 \%$ of DOC export can occur during the highest $10 \%$ of discharge values (Clark et al., 2007; Grand-Clement et al., 2014; Hinton et al., 1997), leading to an underestimation in DOC flux from grab sampled data. Our monitoring dataset recorded only eight samples (of 335 total) in the $Q_{90}$ range, suggesting this will likely have had some impact on the flux estimates. This effect could impact all three sites, however, so further work should address the export of DOC at different sites during peak flows. This limitation reduces the utility of the monitoring dataset for carbon 
budgeting purposes, however the fact that it covers the majority of flow conditions observed with weekly frequency and over a long time period means it is still useful for water treatment planning.

We found generally higher DOC in summer and autumn (Figure 3) when soil microbial activity (Tipping et al., 1999) and autochthonous (George et al., 2007) production are likely to be highest, however the lack of an interactive effect between site and month of the year suggests the effect of season acts equally across the catchment.

As catchments recover from acidification we can expect this to be a less important driver of DOC concentration in the future (Clark et al., 2010), however nitrogen deposition may mean that DOC is higher than the pre-industrial baseline (Sawicka et al., 2017). Catchment management to limit further destabilisation of organic matter offers a possible method of ameliorating these rises (GrandClement et al., 2015) and thus limiting the impact on drinking water treatment. The flux estimates suggest that catchment management schemes focussing on non-peatland areas may also be required given the larger DOC flux in the less peatland influenced areas for the majority of the years we monitored.

\subsection{Catchment survey}

The catchment survey had a monthly sampling frequency and consequently covered only a small proportion of the hydrograph (Figure 4) so can only be considered to be representative of low flow conditions. Interesting conclusions can still be drawn, however, relating to which sub-catchment are responsible for delivery of DOC to the treatment works during these periods. This survey showed that peaty (Spooners), forested (Hangman's Hill) and agricultural (Dart, Thorverton and Washfield) streams represented a significant increase in DOC concentration over the main channel at Simonsbath (Figure 5). This provides evidence for hypothesis b), that there are significant sources of DOC in the non-peatland areas of the catchment, as all but the Spooners site are downstream of the Exebridge monitoring point. Our modelling of DOC based on percentage land use suggested broadleaved woodland, arable, acid grassland, improved grassland and sub-urban to be significant in 
the best model. This suggests both the influence of wooded and agricultural areas, predominantly in the south of the catchment, and the acid grassland in the northerly, peaty headwaters on DOC concentrations. This would add further weight to our hypothesis b) as arable, sub-urban and improved grassland areas are mainly downstream of Exebridge.

Work in nearby catchments in the south-west of England has also suggested that baseflow DOC concentrations can be higher in agricultural catchments than in semi-natural ones (Glendell and Brazier, 2014) due to the addition agricultural amendments to the soil and artificial fertiliser altering the rate of carbon turnover (Chantigny, 2003). These findings agree with other published work suggesting that DOC quantity and quality can be influenced by the extent of riparian wetlands, woodlands and cropland (Wilson and Xenopoulos, 2008; Yang et al., 2017). These data also add weight to the growing need for an understanding of how agriculturally-derived DOC affects catchment carbon budgets, how this may change in the future and how this can be managed for positive water quality outcomes (e.g. Graeber et al., 2015; Stanley et al., 2012).

The comparison of sites in urban areas (Bolham vs. Exe at Tiverton comparison) did not prove to offer significant contributions to DOC concentration, despite the potential for urban runoff and sewage effluent to influence this (Noacco et al., 2017) and inclusion in the ALM results. This is also contrary to the findings of Yang et al., (2017) who noted a significant effect of urban extent on DOC concentrations in their study of 1,402 sites across the USA. This could perhaps be explained by the relatively small size of Tiverton, the main conurbation upstream of the treatment works, which has a population of 21,335 (UK census 2011). Urban runoff and input from sewage treatment works is likely to be small, therefore, compared to the size of the Exe which has a mean discharge of $12.75 \mathrm{~m}^{3}$ $\mathrm{s}^{-1}$ at gauging station 45002, just north of the town (NRFA data). We did, however note a decrease in SUVA in the comparison between sites in the main channel before and after Tiverton (Bolham vs. Exe at Tiverton). This provides evidence for an impact on DOC quality rather than quantity from urban areas, suggesting less aromatic DOC from urban runoff and sewage effluent. Our modelling 
analysis was unable to detect an impact of urban land-use on DOC quality, suggesting at full catchment scale this impact is limited. It should be noted, however, that the sub-catchments used in this modelling did not contain a significant proportion of urban area, hence the need for this direct comparison before and after Tiverton. The lack of an effect comparing mainly rural sub-catchments would seem to suggest the impact of urbanisation on DOC quality is only detectable in significantly urban areas, most likely due to the presence of sewage outflows (Noacco et al., 2017).

We found no effect of aquaculture on DOC quantity or quality, measured by SUVA, suggesting limited impact on downstream water quality. Such sites are regulated in the UK by the Environment Agency and releases to the river are monitored for nutrient and turbidity levels. To our knowledge this is the first study which has looked at the effect of small-scale aquaculture on DOC quantity and quality in UK rivers. The lack of any increase in concentration or change in quality may be due to the use of two settling ponds at the site which are operated in series to reduce turbidity and nutrient loading to the river. The increased residence time, and thus microbial and photolytic processing, likely negates any increase in DOC due to the stocking density of the fish and the use of artificial feed. Sachse et al. (2005) found that fish farms in the River Spree and River Oder in Germany increased the proportion of low molecular weight DOC components which they attributed to autochthonous production in the fish ponds, additions of feed and excretions from the fish themselves. Differences between our study and the work of Sachse et al. (2005) may possibly be explained by the use of settling ponds at our site, differences in farm size and the trophic status of the influent water.

\subsection{Carbon stocks under different land uses}

The data on extractable DOC and microbial persistence suggest riparian areas in woodlands represent large stores of potential DOC flux. This may partly explain the increase in DOC concentration and flux down the catchment which we observed in our monitoring dataset. Riparian soil carbon stores have been highlighted as the major source of riverine DOC (Ledesma et al., 2015), 
whilst a study involving the exclusion of leaf litter from entering a stream suggested that in-stream generation of DOC from benthic litter accounted for approximately $30 \%$ of DOC when compared to a control site (Meyer et al., 1998). Our results suggest that although the amount of extractable DOC produced by litter in the two sub-catchment types is similar, differences in BDOC result in more persistent DOC being exported per $\mathrm{m}^{2}$ litter in woodlands than peatlands.

Our comparison of litter carbon stocks between the peatland site at Spooners and the oak woodland at Tarr Steps suggest a similar amount of autumnal litter production. It is worth noting, however, that sampling took place during leaf-fall in the woodland and therefore these results are likely to be an annual maximum, whereas the peatland site has sources of year-round litter production so is likely to be less seasonal in litter quantity and thus DOC flux (Ritson et al., 2016). Our results on extractable DOC, C:N and BDOC of typical UK oak forest vegetation add to the findings of Pinsonneault et al., (2016) who published similar data for peatland vegetation. Our results suggest comparable BDOC values to peatland species with some exceptions as in our earlier work we noted Sphagnum Spp. produces DOC which is highly labile with BDOC 90\% (Ritson et al., 2016). These data add to the growing body of work needed to understand the likely fate of DOC from different catchment sources.

Our assessment of SOC stocks at the two sites show that Spooners, the peatland site, is vastly greater due to the $\sim 50 x$ higher soil carbon content (Table 5). As well as this, the much greater depth of the organic layer at the peatland site ( $20 \mathrm{~cm}$ for woodland, $\sim 160 \mathrm{~cm}$ for peatland) gives further evidence for the targeting of catchment management programmes seeking to stabilise DOC from these large SOC stocks. It is worth noting, however, that SOC stocks are not the only factor in DOC release as $\mathrm{N}$ fertilisation can play an important role in increasing carbon turnover rate in woodland and arable systems (Chantigny, 2003), resulting in high DOC concentrations. We noted an increase in DOC during the BDOC incubations for the peat soil (Table 5) which were confirmed by repeating these incubations a second time. Increases during BDOC incubations have been noted elsewhere in 
the literature (Moody et al., 2013) and as these occurred exclusively in our most aromatic (indicated by SUVA) samples, we hypothesise this may be due to incomplete conversion to $\mathrm{CO}_{2}$ during the initial measurement at the start of the incubation. This issue remains an area for future research to confirm whether this is an analytical artefact of a genuine increase in DOC.

The analysis of stream water sampled at the same time as the vegetation and soils suggests the peatland site adds low $\mathrm{pH}$, high $\mathrm{DOC}$ water to the main channel, compared to the forested site (Table 6). This is somewhat counteracted by the higher BDOC values meaning a greater proportion of this DOC is likely to be removed in the catchment. This is reflected in the lower DOC concentration and \%BDOC value at Tarr Steps which is in the main channel of the Barle downstream of the Spooners sampling site and therefore contains peatland DOC which has undergone processing. These two points provides evidence for hypothesis $\mathrm{c}$ ), that peatland DOC influence is reduced at the catchment scale by microbial and photolytic processing. It is worth noting, however, that despite a greater proportion of $\mathrm{BDOC}$, the amount of persistent $\mathrm{DOC}$ from the peaty stream is over double that of the forest stream (Table 6), suggesting peat sources are highly important despite significant degradation although further work considering other processes of removal such as flocculation, sedimentation and photodegradation is needed.

\subsection{Synthesis}

Taken together, these three datasets provide significant evidence both for the focus on peatland areas in catchment management aimed at lowering DOC concentrations and the need to also consider other sources of non-peatland DOC in mixed land-use catchments. The results in the catchment survey show that peat influenced headwaters can significantly increase DOC concentrations in the main channel and the results from the BDOC tests show that although a reasonably large proportion of this is biodegradable, the high starting concentration means that large amounts of peat derived DOC will likely reach the treatment works. 
The monitoring dataset, however, also shows increasing DOC concentration and flux down the catchment, suggesting significant inputs of DOC from non-peatland sources under the flow conditions observed. This is particularly relevant for catchments such as ours where abstraction for drinking water production occurs directly from the river, meaning the opportunity for increases in DOC being offset by in-reservoir processing (Köhler et al., 2013) are minimal. Our catchment survey and work on carbon stocks highlight the role of forested areas in providing large potential for the export of persistent DOC from vegetation litter. Agriculturally influenced streams were also shown to be significant (Figure 5 and ALM results) as well as urban sources, however these were not covered in as great detail and identifying the sources of DOC on farms or urban runoff and their persistence remains an area for future work. We would recommend, therefore, that catchment management schemes also consider methods of limiting DOC export from forested and agricultural areas as well at peatlands.

We suggest the increase is DOC flux down the catchment is most likely explained by a combination of our hypotheses a), b) and c) presented in section 4.1 based on our own data and the literature. It is likely that our flux values are under-estimates as our data is under-representative of $Q_{90}$ flows (hypothesis a), however this may affect all sites in a similar manner (Vidon et al., 2008). Further work should explore how the different parts of the catchment respond to peak flows and whether increases in DOC concentration and flux down the catchment remain. We have shown through the catchment survey that significant downstream sources of DOC do exist (hypothesis b) and catchment management options should be considered for both forested and agricultural areas. Finally, we have also demonstrated that peatland DOC is relatively labile and therefore peatland influence decreases with river order in a mixed land-use catchment (hypothesis c). Peatland areas are still highly significant for both carbon budgets and water quality provision, however, due to the high initial concentrations counteracting their relative lability and vast SOC stocks.

\subsection{Conclusions}


- DOC concentration and flux increases downstream from a peaty headwater to a mixed agricultural and forested catchment. Storm sampling is needed to confirm if differences in flux during peak flows alters this relationship

- Sampling of 25 points over a period of twelve months suggest that peaty headwaters, forested, urban and agricultural areas can add higher DOC concentration water to the main channel. We found no effect from small-scale aquaculture but we did detect a change in DOC quality (SUVA) around the main conurbation in the catchment.

- Comparison of carbon stocks showed that vegetation litter in riparian areas of woodlands represent a large source of DOC that is relatively recalcitrant to microbial degradation, and therefore a likely additional source of DOC to river systems. SOC stocks in peatlands are much greater than in woodland areas, justifying interventions in order to stabilise carbon losses from them.

\section{Acknowledgements}

This work was supported by the Engineering and Physical Sciences Research Council Twenty-65 project [Grant number EP/ N010124/1]. Brazier acknowledges the support of the South West Water funded Mires-on-the-Moors project. Croft acknowledges the support of The Centre for Doctoral Training in Sustainable Civil Engineering and the Dixon award. The authors would also like to thank South West Water and especially the Mires project staff for access to sites as well as the Exmoor National Park Authority and Natural England.

\section{Competing interests}

The authors declare no competing financial interests. 


\section{References}

Aitkenhead, J.A., McDowell, W.H., 2000. Soil C:N ratio as a predictor of annual riverine DOC flux at local and global scales. Global Biogeochem. Cycles 14, 127-138.

Billett, M.F., Charman, D.J., Clark, J.M., Evans, C.D., Evans, M.G., Ostle, N.J., Worrall, F., Burden, A., Dinsmore, K.J., Jones, T., McNamara, N.P., Parry, L., Rowson, J.G., Rose, R., 2010. Carbon balance of UK peatlands: current state of knowledge and future research challenges. Clim. Res. 45, 13-29.

Bonn, A., Reed, M.S., Evans, C.D., Joosten, H., Bain, C., Farmer, J., Emmer, I., Couwenberg, J., Moxey, A., Artz, R., Tanneberger, F., Unger, M. Von, Smyth, M., Birnie, D., 2014. Investing in nature: Developing ecosystem service markets for peatland restoration. Ecosyst. Serv. 9, 54-65. https://doi.org/10.1016/j.ecoser.2014.06.011

Chantigny, M.H., 2003. Dissolved and water-extractable organic matter in soils: A review on the influence of land use and management practices. Geoderma 113, 357-380.

https://doi.org/10.1016/S0016-7061(02)00370-1

Clark, J., Bottrell, S.H., Evans, C.D., Monteith, D.T., Bartlett, R., Rose, R., Newton, R.J., Chapman, P.J., 2010. The importance of the relationship between scale and process in understanding long-term DOC dynamics. Sci. Total Environ. 408, 2768-75.

https://doi.org/10.1016/j.scitotenv.2010.02.046

Clark, J., Chapman, P., Heathwaite, A., Adamson, J., 2006. Suppression of dissolved organic carbon by sulfate induced acidification during simulated droughts. Environ. Sci. Technol. 40, 1776-1783.

Clark, J., Lane, S., Chapman, P., Adamson, J., 2007. Export of dissolved organic carbon from an upland peatland during storm events: Implications for flux estimates. J. Hydrol. 347, 438-447. https://doi.org/10.1016/j.jhydrol.2007.09.030

Cole, J.J., Prairie, Y.T., Caraco, N.F., McDowell, W.H., Tranvik, L.J., Striegl, R.G., Duarte, C.M., Kortelainen, P., Downing, J. a., Middelburg, J.J., Melack, J., 2007. Plumbing the Global Carbon Cycle: Integrating Inland Waters into the Terrestrial Carbon Budget. Ecosystems 10, 172-185. https://doi.org/10.1007/s10021-006-9013-8

Creed, I.F., Mcknight, D.M., Pellerin, B.A., Green, M.B., Bergamaschi, B.A., Aiken, G.R., Burns, D.A., Findlay, S.E.G., Shanley, J.B., Striegl, R.G., Aulenbach, B.T., Clow, D.W., Laudon, H., Mcglynn, B.L., Mcguire, K.J., Smith, R.A., Stackpoole, S.M., 2015. The river as a chemostat: fresh perspectives on dissolved organic matter flowing down the river continuum. Can. J. Fish. Aquat. Sci. 14, 1-14.

Edzwald, J., 1993. Coagulation in drinking water treatment: Particles, Organics and Coagulants. Water Sci. Technol. 27, 21-35.

Eikebrokk, B., Vogt, R.D., Liltved, H., 2004. NOM increase in Northern European source waters : discussion of possible causes and impacts on coagulation / contact filtration processes. Water Sci. Technol. Water Supply 4, 47-54.

Freeman, C., Ostle, N., Kang, H., 2001. An enzymic "latch" on a global carbon store. Nature 409, 149. https://doi.org/10.1038/35051650

George, G., Hurley, M., Hewitt, D., 2007. The impact of climate change on the physical characteristics of the larger lakes in the English Lake District. Freshw. Biol. 52, 1647-1666. https://doi.org/10.1111/j.1365-2427.2007.01773.x 
Glendell, M., Brazier, R.E., 2014. Accelerated export of sediment and carbon from a landscape under intensive agriculture. Sci. Total Environ. 476-477, 643-656.

https://doi.org/10.1016/j.scitotenv.2014.01.057

Graeber, D., Goyenola, G., Meerhoff, M., Zwirnmann, E., Ovesen, N.B., Glendell, M., Gelbrecht, J., Teixeira De Mello, F., González-Bergonzoni, I., Jeppesen, E., Kronvang, B., 2015. Interacting effects of climate and agriculture on fluvial DOM in temperate and subtropical catchments. Hydrol. Earth Syst. Sci. 19, 2377-2394. https://doi.org/10.5194/hess-19-2377-2015

Grand-Clement, E., Anderson, K., Smith, D., Angus, M., Luscombe, D.J., Gatis, N., Bray, L.S., Brazier, R.E., 2015. New approaches to the restoration of shallow marginal peatlands. J. Environ. Manage. 161, 417-430. https://doi.org/10.1016/j.jenvman.2015.06.023

Grand-Clement, E., Anderson, K., Smith, D., Luscombe, D., Gatis, N., Ross, M., Brazier, R.E., 2013. Evaluating ecosystem goods and services after restoration of marginal upland peatlands in South-West England. J. Appl. Ecol. 50, 324-334. https://doi.org/10.1111/13652664.12039

Grand-Clement, E., Luscombe, D.J., Anderson, K., Gatis, N., Benaud, P., Brazier, R.E., 2014. Antecedent conditions control carbon loss and downstream water quality from shallow, damaged peatlands. Sci. Total Environ. 493, 961-73.

https://doi.org/10.1016/j.scitotenv.2014.06.091

Hinton, M.J., Schiff, S.L., English, M.C., 1997. The significance of storms for the concentration and export of dissolved organic carbon from two Precambrian Shield catchments. Biogeochemistry 36, 67-88. https://doi.org/10.1023/A:1005779711821

Hope, D., Billett, M.F., Cresser, M.S., 1997. Exports of organic carbon in two river systems in NE Scotland. J. Hydrol. 193, 61-82. https://doi.org/10.1016/S0022-1694(96)03150-2

Jones, T.G., Evans, C.D., Jones, D.L., Hill, P.W., Freeman, C., 2016. Transformations in DOC along a source to sea continuum; impacts of photo-degradation, biological processes and mixing. Aquat. Sci. 78, 433-446. https://doi.org/10.1007/s00027-015-0461-0

Köhler, S.J., Kothawala, D., Futter, M.N., Liungman, O., Tranvik, L., 2013. In-lake processes offset increased terrestrial inputs of dissolved organic carbon and color to lakes. PLoS One 8, e70598. https://doi.org/10.1371/journal.pone.0070598

Ledesma, J.L.J., Grabs, T., Bishop, K.H., Schiff, S.L., Köhler, S.J., 2015. Potential for longterm transfer of dissolved organic carbon from riparian zones to streams in boreal catchments. Glob. Chang. Biol. 1-17. https://doi.org/10.1111/gcb.12872

McDowell, W.H., Zsolnay, a., Aitkenhead-Peterson, J. a., Gregorich, E.G., Jones, D.L., Jödemann, D., Kalbitz, K., Marschner, B., Schwesig, D., 2006. A comparison of methods to determine the biodegradable dissolved organic carbon from different terrestrial sources. Soil Biol. Biochem. 38, 1933-1942. https://doi.org/10.1016/j.soilbio.2005.12.018

Meyer, J.L., Wallace, J.B., Eggert, S.L., 1998. Leaf Litter as a Source of Dissolved Organic Carbon in Streams 240-249.

Monteith, D.T., Stoddard, J.L., Evans, C.D., de Wit, H.A., Forsius, M., Høgåsen, T., Wilander, A., Skjelkvåle, B.L., Jeffries, D.S., Vuorenmaa, J., Keller, B., Kopácek, J., Vesely, J., 2007. Dissolved organic carbon trends resulting from changes in atmospheric deposition chemistry. Nature 450, 537-40. https://doi.org/10.1038/nature06316

Moody, C.S., Worrall, F., Evans, C.D., Jones, T.G., 2013. The rate of loss of dissolved organic carbon (DOC) through a catchment. J. Hydrol. 492, 139-150.

https://doi.org/10.1016/j.jhydrol.2013.03.016 
Nieuwenhuijsen, M.J., Grellier, J., Smith, R., Iszatt, N., Bennett, J., Best, N., Toledano, M., 2009. The epidemiology and possible mechanisms of disinfection by-products in drinking water. Philos. Trans. A. Math. Phys. Eng. Sci. 367, 4043-76.

https://doi.org/10.1098/rsta.2009.0116

Noacco, V., Wagener, T., Worrall, F., Burt, T.P., Howden, N., 2017. Human impact on longterm organic carbon export to rivers. Biogeosciences 122, 1-19.

https://doi.org/10.1002/2016JG003614

Palmer, S.M., Evans, C.D., Chapman, P.J., Burden, A., Jones, T.G., Allott, T.E.H., Evans, M.G., Moody, C.S., Worrall, F., Holden, J., 2016. Sporadic hotspots for physico-chemical retention of aquatic organic carbon: from peatland headwater source to sea. Aquat. Sci. 78, 491-504. https://doi.org/10.1007/s00027-015-0448-x

Parry, L.E., Holden, J., Chapman, P.J., 2014. Restoration of blanket peatlands. J. Environ. Manage. 133, 193-205. https://doi.org/10.1016/j.jenvman.2013.11.033

Pinsonneault, A.J., Moore, T.R., Roulet, N.T., Lapierre, J.F., 2016. Biodegradability of Vegetation-Derived Dissolved Organic Carbon in a Cool Temperate Ombrotrophic Bog. Ecosystems 19, 1023-1036. https://doi.org/10.1007/s10021-016-9984-z

Ritson, J., Graham, N., Templeton, M.R., Clark, J.M., Gough, R., Freeman, C., 2014. The impact of climate change on the treatability of dissolved organic matter (DOM) in upland water supplies: A UK perspective. Sci. Total ... 473-474, 714-730.

Ritson, J.P., Bell, M., Brazier, R.E., Grand-clement, E., Graham, N.J.D., Freeman, C., Smith, D., Templeton, M.R., Clark, J.M., 2016. Managing peatland vegetation for drinking water treatment. Sci. Rep. 6:36751. https://doi.org/10.1038/srep36751

Rowland, C.S., Morton, R.D., Carrasco, L., McShane, G., O'Neil, A.W., Wood, C.M. (2017) Land Cover Map 2015 (25m raster, GB). NERC Environmental Information Data Centre. https://doi.org/10.5285/bb15e200-9349-403c-bda9-b430093807c7

Sachse, A., Henrion, R., Gelbrecht, J., Steinberg, C., 2005. Classification of dissolved organic carbon (DOC) in river systems: Influence of catchment characteristics and autochthonous processes. Org. Geochem. 36, 923-935.

https://doi.org/10.1016/j.orggeochem.2004.12.008

Salama, N.K.G., Murray, A.G., 2011. Farm size as a factor in hydrodynamic transmission of pathogens in aquaculture fish production. Aquac. Environ. Interact. 2, 61-74.

https://doi.org/10.3354/aei00030

Sawicka, K., Rowe, E.C., Evans, C.D., Monteith, D.T., E.I.Vanguelova, Wade, A.J., J.M.Clark, 2017. Modelling impacts of atmospheric deposition and temperature on long-term DOC trends. Sci. Total Environ. 578, 323-336.

https://doi.org/10.1016/j.scitotenv.2016.10.164

Stanley, E.H., Powers, S.M., Lottig, N.R., Buffam, I., Crawford, J.T., 2012. Contemporary changes in dissolved organic carbon (DOC) in human-dominated rivers: Is there a role for DOC management? Freshw. Biol. 57, 26-42. https://doi.org/10.1111/j.1365-

2427.2011.02613.x

Stolbovoy, V., Montanarella, L., Jones, A., Gallego, J., 2007. SOIL SAMPLING PROTOCOL TO CERTIFY THE CHANGES OF ORGANIC CARBON STOCK IN MINERAL SOIL OF THE EUROPEAN UNION: Version 2. European Comission, EUR 21576 EN/2.

Tipping, E., Woof, C., Rigg, E., Harrison, a, Ineson, P., Taylor, K., Benham, D., Poskitt, J., Rowland, a, Bol, R., 1999. Climatic influences on the leaching of dissolved organic matter 
from upland UK moorland soils, investigated by a field manipulation experiment. Environ. Int. 25, 83-95. https://doi.org/10.1016/S0160-4120(98)00098-1

Vidon, P., Wagner, L.E., Soyeux, E., 2008. Changes in the character of DOC in streams during storms in two Midwestern watersheds with contrasting land uses. Biogeochemistry 88, 257-270. https://doi.org/10.1007/s10533-008-9207-6

Walling, D.E., Webb, B.W., 1985. Estimating the discharge of contaminants to coastal waters by rivers: Some cautionary comments. Mar. Pollut. Bull. 16, 488-492. https://doi.org/10.1016/0025-326X(85)90382-0

Weishaar, J.L., Aiken, G.R., Bergamaschi, B.A., Fram, M.S., Fujii, R., Mopper, K., 2003. Evaluation of specific ultraviolet absorbance as an indicator of the chemical composition and reactivity of dissolved organic carbon. Environ. Sci. Technol. 37, 4702-8.

Wellock, M.L., Reidy, B., Laperle, C.M., Bolger, T., Kiely, G., 2011. Soil organic carbon stocks of afforested peatlands in Ireland. Forestry 84, 441-451.

https://doi.org/10.1093/forestry/cpr046

Wilson, H.F., Xenopoulos, M. a., 2008. Effects of agricultural land use on the composition of fluvial dissolved organic matter. Nat. Geosci. 2, 37-41. https://doi.org/10.1038/ngeo391

Worrall, F., Armstrong, A., Holden, J., 2007. Short-term impact of peat drain-blocking on water colour, dissolved organic carbon concentration, and water table depth. J. Hydrol. 337, 315-325. https://doi.org/10.1016/j.jhydrol.2007.01.046

Worrall, F., Howden, N.J.K., Burt, T.P., Bartlett, R., 2018. Declines in the dissolved organic carbon (DOC) concentration and flux from the UK. J. Hydrol. 556, 775-789.

https://doi.org/10.1016/j.jhydrol.2017.12.001

Yang, Q., Zhang, X., Xu, X., Asrar, G.R., 2017. An Analysis of Terrestrial and Aquatic Environmental Controls of Riverine Dissolved Organic Carbon in the Conterminous United States. Water 9, 383. https://doi.org/10.3390/w9060383

Yates, C.A., Johnes, P.J., Spencer, R.G.M., 2016. Assessing the drivers of dissolved organic matter export from two contrasting lowland catchments, U.K. Sci. Total Environ. 569-570, 1330-1340. https://doi.org/10.1016/j.scitotenv.2016.06.211

Yu, T., Minayeva, T.Y., Bragg, O.M., Sirin, A.A., 2017. Towards ecosystem-based restoration of peatland biodiversity. Mires Peat 19, 1-36.

https://doi.org/10.19189/MaP.2013.OMB.150 
Table 1: Descriptive statistics comparing daily flow (Exe at Thorverton: 45001) with grab sampled data for the period 2012 2017.

\begin{tabular}{|c|c|c|}
\hline & $\begin{array}{c}\text { Gauged daily flow } \\
\left(\mathrm{m}^{\mathbf{3}} \mathbf{s}^{-\mathbf{1}}\right)\end{array}$ & $\begin{array}{c}\text { Grab sample } \\
\left(\mathrm{m}^{\mathbf{3}} \mathbf{s}^{-\mathbf{1}}\right)\end{array}$ \\
\hline $\mathbf{n}$ & 2,558 & 337 \\
\hline Mean & $17.26 \pm 0.44$ & $17.57 \pm 1.23$ \\
\hline $\mathbf{Q}_{\mathbf{2 5}}$ & 4.49 & 4.27 \\
\hline $\mathbf{Q}_{50}$ & 9.11 & 8.32 \\
\hline $\mathbf{Q}_{75}$ & 23.08 & 22.14 \\
\hline Skew & $3.14 \pm 0.05$ & $2.95 \pm 0.13$ \\
\hline
\end{tabular}


Table 2: DOC flux estimates for the three sites on the River Exe, UK.

\begin{tabular}{|c|c|c|c|}
\hline Site & $\begin{array}{c}\text { Exebridge } \\
\left(\mathbf{k g ~ h}^{-1} \text { year }^{-1}\right)\end{array}$ & $\begin{array}{c}\text { Bolham } \\
\left(\mathbf{k g ~ h}^{-1} \text { year }^{-1}\right)\end{array}$ & $\begin{array}{c}\text { Brampford Speke } \\
\left.\text { (kg ha }^{-1} \text { year }^{-1}\right)\end{array}$ \\
\hline $\mathbf{2 0 1 2}$ & $47.89 \pm 2.14$ & $43.11 \pm 1.36$ & $55.34 \pm 2.16$ \\
\hline $\mathbf{2 0 1 3}$ & $18.53 \pm 0.74$ & $19.67 \pm 0.82$ & $26.73 \pm 1.20$ \\
\hline $\mathbf{2 0 1 4}$ & $16.53 \pm 1.41$ & $20.91 \pm 0.97$ & $25.93 \pm 1.06$ \\
\hline $\mathbf{2 0 1 5}$ & $31.98 \pm 1.66$ & $28.57 \pm 1.07$ & $28.13 \pm 1.04$ \\
\hline $\mathbf{2 0 1 6}$ & $33.60 \pm 2.96$ & $21.24 \pm 0.79$ & $21.42 \pm 0.73$ \\
\hline $\mathbf{2 0 1 7}$ & $15.87 \pm 0.42$ & $16.51 \pm 0.27$ & $17.13 \pm 0.50$ \\
\hline
\end{tabular}


Table 3: Descriptive statistics comparing daily flow with grab sampled data for the period Nov 16 to Oct 17.

\begin{tabular}{|c|c|c|}
\hline & $\begin{array}{c}\text { Gauged daily flow } \\
\left(\mathbf{m}^{\mathbf{3}} \mathbf{s}^{-\mathbf{1}}\right)\end{array}$ & $\begin{array}{c}\text { Grab sample } \\
\left(\mathbf{m}^{\mathbf{3}} \mathbf{s}^{-\mathbf{1}}\right)\end{array}$ \\
\hline $\mathbf{n}$ & 336 & 12 \\
\hline Mean & $11.32 \pm 0.80$ & $7.82 \pm 1.12$ \\
\hline $\mathbf{Q}_{\mathbf{2 5}}$ & 4.36 & 3.87 \\
\hline $\mathbf{Q}_{\mathbf{5 0}}$ & 7.24 & 8.39 \\
\hline $\mathbf{Q}_{\mathbf{7 5}}$ & 12.05 & 10.92 \\
\hline Skew & $5.98 \pm 0.13$ & $0.40 \pm 0.64$ \\
\hline
\end{tabular}


Table 4: Litter and extractable DOC chemistry of dominant species at Tarr Steps site $(n=5)$.

\begin{tabular}{|c|c|c|c|c|c|}
\hline Litter type & C:N & $\begin{array}{c}\text { WEOM } \\
\left(\mathrm{mg}^{-C} \mathrm{~g}^{-1}\right)\end{array}$ & $\begin{array}{c}\text { BDOC } \\
(\%)\end{array}$ & $\mathrm{pH}$ & $\begin{array}{c}\text { SUVA } \\
\left(\mathrm{mg}^{-1} \mathrm{~m}^{-1}\right)\end{array}$ \\
\hline $\begin{array}{c}\text { Hazel } \\
\text { (Corylus avellana) }\end{array}$ & $\begin{array}{r}42.19 \\
\pm 0.07\end{array}$ & $\begin{array}{r}55.09 \\
\pm 1.41\end{array}$ & $\begin{array}{r}9.5 \\
\pm 1.1\end{array}$ & $\begin{array}{r}5.47 \\
\pm 0.03\end{array}$ & $\begin{array}{r}2.00 \\
\pm 0.15\end{array}$ \\
\hline $\begin{array}{c}\text { Braken } \\
\text { (Pteridum aquilinum) }\end{array}$ & $\begin{array}{r}40.63 \\
\pm 0.03\end{array}$ & $\begin{array}{r}38.56 \\
\pm 3.30\end{array}$ & $\begin{array}{r}59.1 \\
\pm 4.5\end{array}$ & $\begin{array}{r}5.49 \\
\pm 0.02\end{array}$ & $\begin{array}{r}2.10 \\
\pm 0.13\end{array}$ \\
\hline $\begin{array}{c}\text { Beech } \\
\text { (Fagus sylvatica) }\end{array}$ & $\begin{array}{r}47.26 \\
\pm 0.13\end{array}$ & $\begin{array}{r}30.17 \\
\pm 1.35\end{array}$ & 46.4 & $\begin{array}{r}5.51 \\
\pm 0.05\end{array}$ & $\begin{array}{r}2.10 \\
\pm 0.07\end{array}$ \\
\hline $\begin{array}{c}\text { Oak } \\
\text { (Quercus petraea) }\end{array}$ & $\begin{array}{r}49.07 \\
\pm 0.14\end{array}$ & $\begin{array}{r}49.26 \\
\pm 4.66\end{array}$ & $\begin{array}{r}20.8 \\
\pm 6.6\end{array}$ & $\begin{array}{r}5.25 \\
\pm 0.04\end{array}$ & $\begin{array}{r}1.53 \\
\pm 0.07\end{array}$ \\
\hline
\end{tabular}


Table 5: Soil chemistry and DOC for two soil depths at the peatland and forested site $(n=5)$.

\begin{tabular}{|c|c|c|c|c|c|c|c|c|}
\hline & $\begin{array}{l}\text { Soil bulk } \\
\text { density } \\
\left(\mathrm{g} \mathrm{cm}^{-3}\right)\end{array}$ & $\begin{array}{c}\text { Soil C } \\
\text { (\%) }\end{array}$ & $\begin{array}{l}\text { Soil } \\
\text { C:N }\end{array}$ & $\begin{array}{l}\text { LOI } \\
\text { (\%) }\end{array}$ & $\begin{array}{l}\text { WEOM } \\
\left(\mathrm{mg}-\mathrm{C}^{-1}\right)\end{array}$ & $\begin{array}{c}\text { BDOC } \\
\text { (\%) }\end{array}$ & $\begin{array}{c}\text { SUVA } \\
\left(\mathrm{L} \mathrm{mg}^{-1} \mathrm{~m}\right. \\
\left.{ }^{1}\right)\end{array}$ & $\mathrm{pH}$ \\
\hline Spooners & 0.076 & 52.94 & 20.47 & 94.7 & 0.59 & -40.0 & 14.9 & 6.09 \\
\hline $0-10 \mathrm{~cm}$ & \pm 0.004 & \pm 1.03 & \pm 0.48 & \pm 0.3 & \pm 0.04 & \pm 4.5 & \pm 1.2 & \pm 0.05 \\
\hline Spooners & 0.085 & 52.93 & 19.12 & 94.9 & 0.62 & -16.2 & 21.1 & 6.20 \\
\hline $10-20 \mathrm{~cm}$ & \pm 0.005 & \pm 0.59 & \pm 0.44 & \pm 0.1 & \pm 0.11 & \pm 5.2 & \pm 2.2 & \pm 0.04 \\
\hline Tarr Steps & 1.051 & 2.93 & 13.30 & 14.2 & 34.14 & 58.6 & 1.3 & 4.09 \\
\hline $0-10 \mathrm{~cm}$ & \pm 0.055 & \pm 1.53 & \pm 0.58 & \pm 1.8 & \pm 2.13 & \pm 3.1 & \pm 0.1 & \pm 0.10 \\
\hline Tarr Steps & 1.253 & 0.94 & 11.06 & 7.8 & 19.94 & 57.3 & 1.2 & 4.42 \\
\hline $10-20 \mathrm{~cm}$ & \pm 0.034 & \pm 0.28 & \pm 0.41 & \pm 0.1 & \pm 1.70 & \pm 2.6 & \pm 0.1 & \pm 0.11 \\
\hline
\end{tabular}


Table 6 Water parameters from $n=4$ grab samples collected alongside soil and vegetation surveys at low flow conditions.

\begin{tabular}{|c|c|c|c|c|}
\hline Site & $\mathbf{p H}$ & $\begin{array}{c}\text { DOC } \\
\left(\mathbf{m g ~ l}^{-\mathbf{1}}\right)\end{array}$ & $\begin{array}{c}\text { SUVA } \\
\left(\mathbf{L ~ m g ~}^{-1} \mathbf{~ m}^{-1}\right)\end{array}$ & $\begin{array}{c}\text { BDOC } \\
\mathbf{( \% )}\end{array}$ \\
\hline Spooners & 5.63 & 5.30 & 4.05 & 45.0 \\
& \pm 0.03 & \pm 0.89 & \pm 0.43 & \pm 6.1 \\
\hline Tarr Steps & 7.37 & 1.03 & 4.36 & 17.6 \\
& \pm 0.02 & \pm 0.04 & \pm 0.12 & \pm 2.8 \\
\hline Forest stream & 7.34 & 1.43 & 3.47 & 25.7 \\
& \pm 0.01 & \pm 0.04 & \pm 0.14 & \pm 4.0 \\
\hline
\end{tabular}




\section{Highlights}

- Peatland, agricultural and woodland sub-catchments increase DOC concentrations.

- Biodegradability means more persistent DOC from woodland litter vs peatland.

- No impact from small-scale aquaculture.

- Catchment management should consider all sources of DOC within a catchment. 

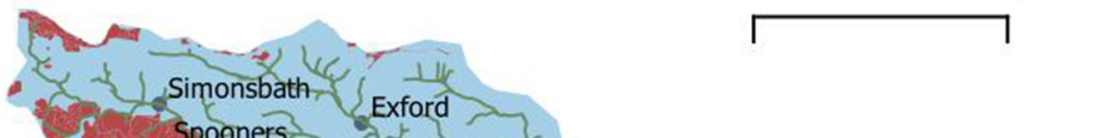

Spooners

Withypool

Exe Quarme Quarme
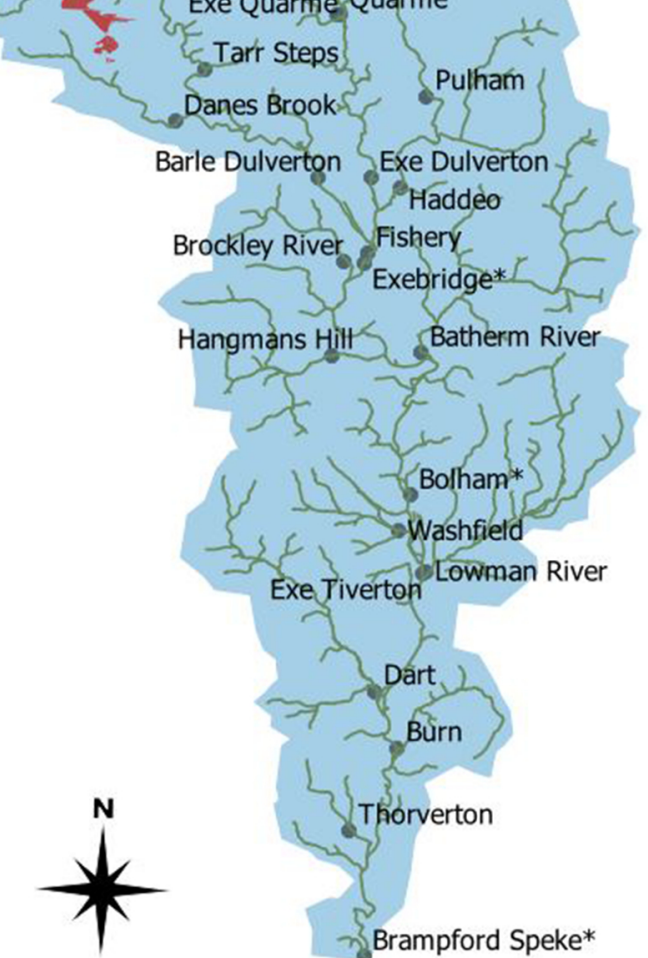

Exe Tiverton Lowman River

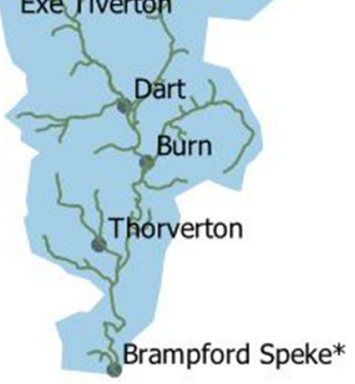

Figure 1 


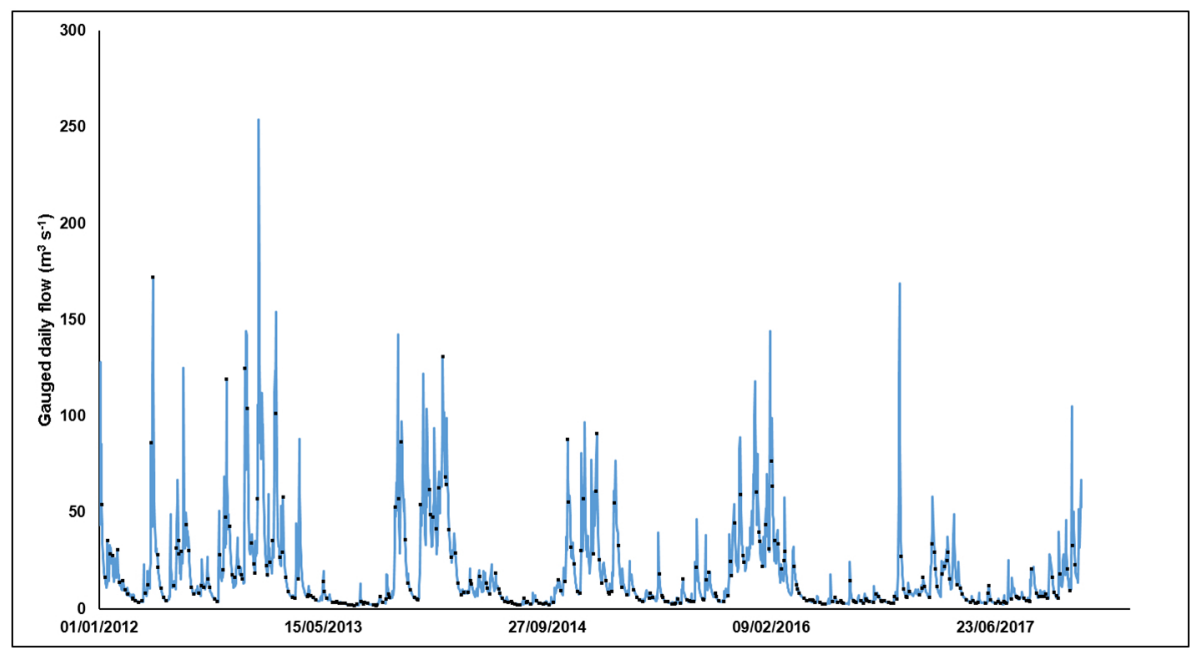

Figure 2 


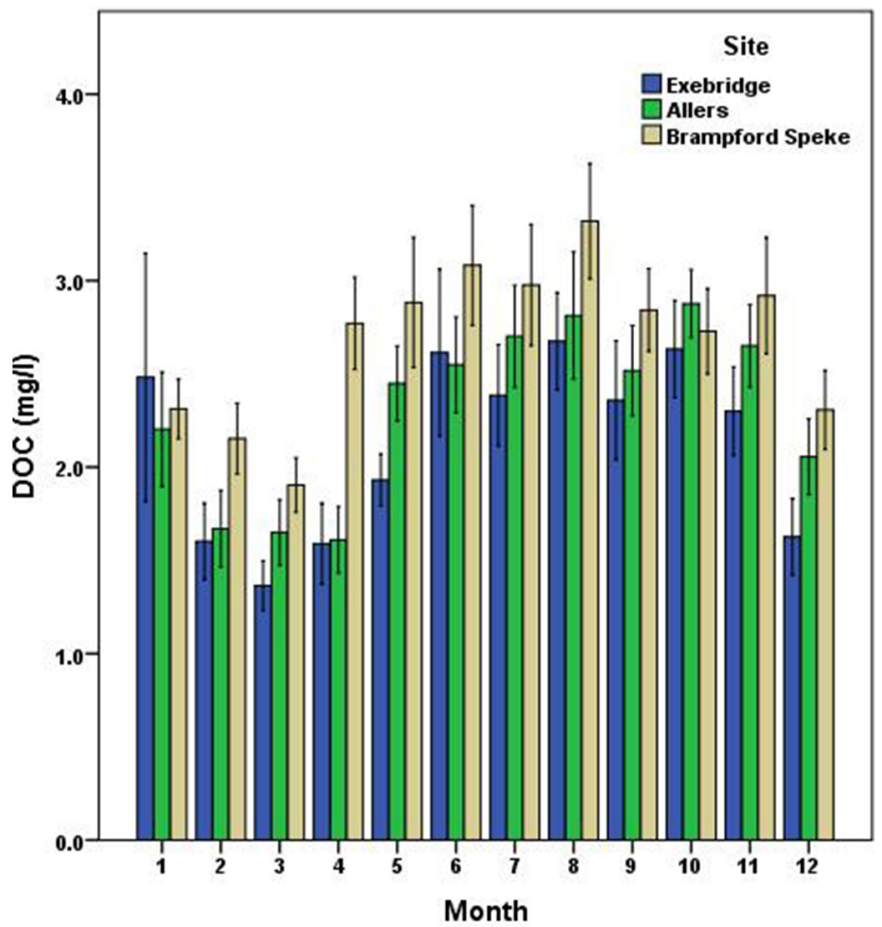

Figure 3 


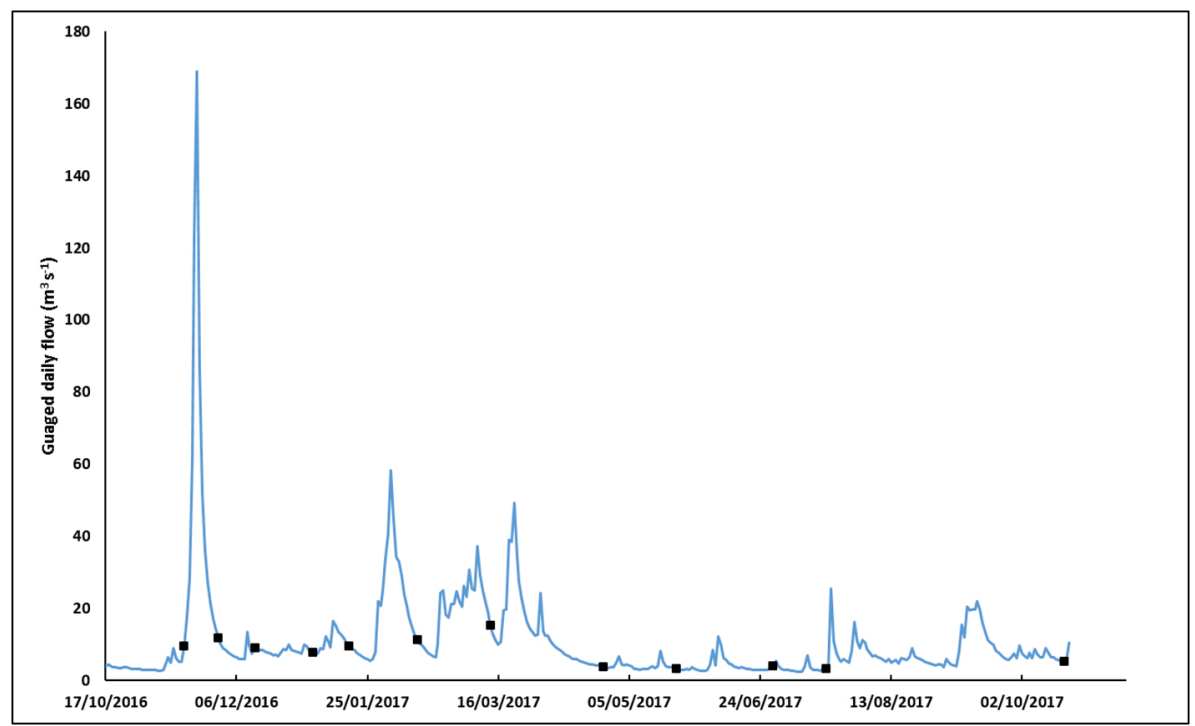

Figure 4 


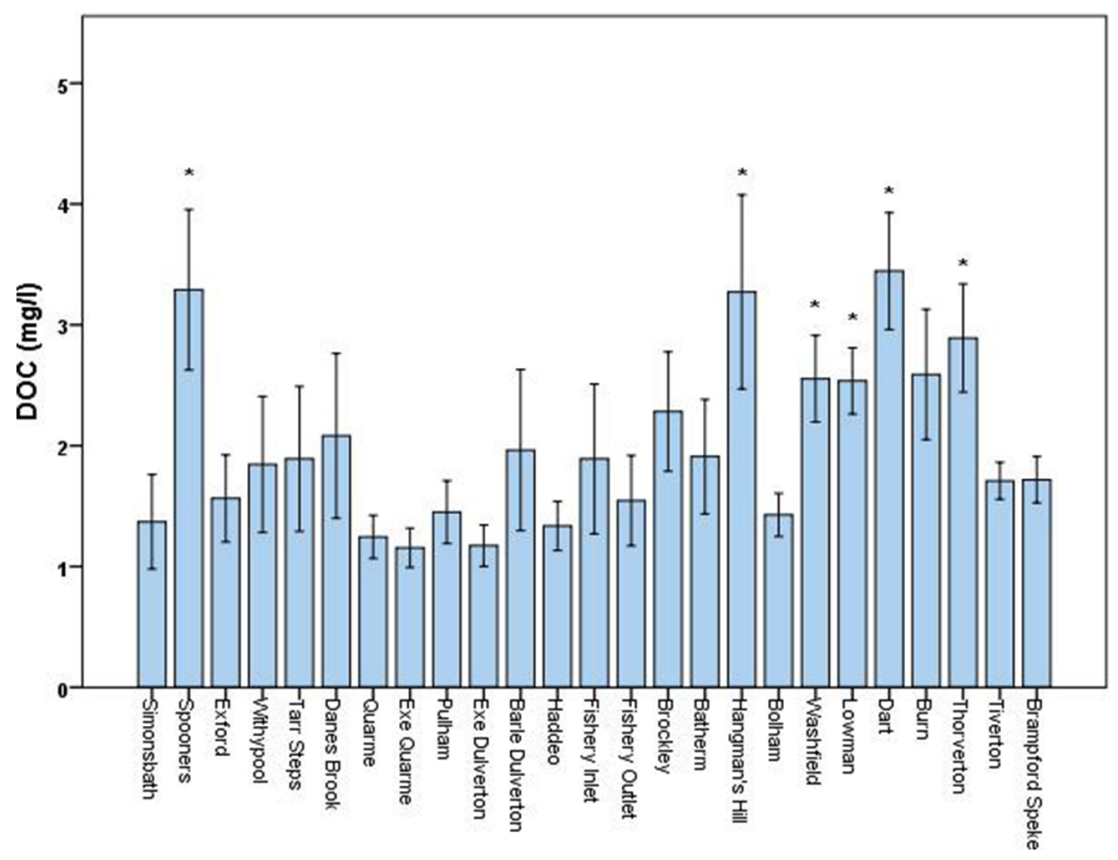

Figure 5 